\title{
Dos "Confesiones": Las del beato Orozco y las de san Agustín
}

El género literario de las Confesiones tiene a San Agustín por creador. Su obra significó una novedad por el título en sí mismo, desconocido hasta entonces; por su forma, en cuanto concebida como plegaria, y por su contenido como autobiografía y específicamente como autobiografía religiosa 1.

El género literario alcanzó la perfección en su mismo nacimiento. Quizá ésta haya sido una de las razones que explique que no haya tenido demasiados imitadores. Pero no han faltado. Algunos en clave profana ${ }^{2}$, otros en versión religiosa, más en línea con el modelo ${ }^{3}$. Uno de estos últimos ha sido el Beato Alonso de Orozco, religioso que profesó como norma de su vida la codificada en la Regla del Obispo de Hipona e institucionalizada en la Orden de San Agustín.

En su amplia producción bibliográfica se cuenta una obra intitulada Confesiones ${ }^{4}$. Era fácil intuir que la inspiración para escribirla le había llegado de la lectura de la del Obispo de Hipona. Mas, por si fuera necesario, el mismo Fr. Alonso declara explícitamente su intención de imitar al Santo 5. Indiscutible el hecho, cabe establecer una comparación entre ambos escritos

1. Entendemos biografía en sentido amplio y genérico, en cuanto que aporta datos biográficos. Es de todos conocida la discrepancia entre los estudiosos sobre si la obra ha de considerarse propiamente como autobiografía o no. Cf.. L. VERHEIJEN, Eloquentia pedisequa. Observations sur le style des Confessions de St. Augustin. Nimega 1949, que examina las tomas de posición hasta aquel momento. La suya queda fijada en estas palabras: "Nous sommes d'avis que les Confessions doivent être regardées, non comme une autobiographie, mais comme une oeuvre sui generis, quoique ayant des contacts matériels avec l'autobiographie" (p. 74).

2. La obra más célebre es, sin duda, la de J.J.Rousseau, Las Confesiones. Espasa Calpe, Madrid 1979.

3. Evidentemente, no todos los escritos de carácter autobiográfico-espiritual han de asimilarse a las Confesiones. Cf. Dictionnaire de Spiritualité, I, pp. 1145-1158: Principales autobiographies (spirituelles).

4. Obra que, curiosamente, no aparece mencionada entre las autobiografías espirituales en el Dictionnaire de Spiritualité (cf. nota anterior).

5. "Queriendo yo, pecador, imitar en algo la grande humildad de vuestro gran siervo, mi Padre San Agustín, el cual hizo trece libros de sus Confesiones, para gloria vuestra y ejemplo de los cristianos..." (Prólogo). 
para determinar si realmente consigue su propósito, qué niveles alcanza, o, dicho de otra manera, hasta dónde llega la dependencia, en caso de darse, del religioso agustino respecto a su santo Fundador por lo que a dicha obra se refiere.

En efecto, la intención expresada por el Beato de querer imitar al Santo implica un cierto "entrañamiento". Con todo, no puede olvidarse que, aunque con título idéntico, se trata de obras de dos autores distintos y compuestas en épocas no sólo distintas, sino también muy alejadas en el tiempo entre sí, por lo que tiene que darse necesariamente un extrañamiento entre ambas. Ver hasta dónde llegan extrañamiento y "entrañamiento" es lo que nos proponemos examinar. Nuestro intento no es hacer un estudio comparativo exhaustivo, sino limitado a ciertos aspectos 6 .

Anticipamos ya unas conclusiones de carácter muy general, que a continuación intentaremos especificar y desarrollar. La primera afirma la indudable presencia de la obra agustiniana en la orozquiana. La segunda certifica la neta diferencia entre ambos escritos. El extrañamiento supera con mucho, a nuestro parecer, el "entrañamiento". Es decir, el éxito en la imitación nos parece bastante relativo ${ }^{7}$.

\section{DEPENDENCIA TEXTUAL.}

En su obra el Beato menciona nominalmente a San Agustín como escritor en cinco ocasiones; pero, si exceptuamos el prólogo en que hace referencia a las Confesiones ${ }^{8}$, no da el nombre de ninguna otra obra.

Los editores han procurado precisar a qué obras se refiere el Beato cuando cita al santo Obispo. Como en ningún modo pretendían hacer labor crítica, no cabe sorprenderse de que el resultado no sea satisfactorio para el erudito moderno. Por una parte, se limitan a los textos en que el Beato menciona explícitamente al Santo (y esto no siempre ${ }^{9}$ ), sin preocuparse de perseguir otras referencias implícitas. Respecto a las Confesiones sólo señalan una sola ${ }^{10}$. Veamos qué resultados nos depara un examen más detenido.

6. Por otra parte, nos limitamos a lo que es propiamente el libro de las Confesiones, excluyendo la relación de favores que sigue en las distintas ediciones.

7. Tomado en términos absolutos, pues no se nos pasa por alto que el intento de imitación, tal como lo expresa el Beato, se limita al aspecto específico de su humildad, pensando en procurar la gloria de Dios y servir de ejemplo a los cristianos.

8. Cf. nota 5 . Los otros pasajes son: 1,$4 ; 2,5 ; 2,9 ; 2,10$.

9. Por ejemplo, la edición realizada en la imprenta del Venerable Siervo de Dios Fray Alonso de Orozco en Madrid en 1736 no ofrece referencia alguna para los capítulos 2,5 (=Sermón 105,7$)$ y 2,9 (=Soliloquios $1,10,17$ ). La edición de la Imprenta de Amigos del País de Manila 1882, tampoco ofrece referencia para el primer texto.

10. La edición de Madrid de 1736 sólo señala la de 2,10, dando además una referencia errónea (como veremos, no se trata del libro noveno, sino del octavo). Dígase lo mismo de la edición de Manila 1882, que ya es más detallada en las referencias. 
Dejamos de lado, por demasiado obvia, la primera referencia, presente en el título mismo, que se lo inspiró, como ya anotamos, la obra homónima agustiniana. Aunque su mención explícita sólo acontezca en el prólogo, la cita textualmente en un par de ocasiones. En un caso, con mención expresa del nombre del Santo; en otro, recurriendo a un circunloquio. La primera aparece en el libro primero, se refiere asimismo al libro primero de las Confesiones agustinianas, pero se trata de una cita indirecta. He aquí cómo escribe el Beato: "Admírase mi Padre San Agustín y escribe: Dios mío, ¿de nada tenéis necesidad, y os alegráis con las ganancias? ¿A nadie habéis menester, y pedís usura de vuestros dones?" $(1,4)$. Acabamos se señalar que se trata de una cita indirecta. En efecto, el texto lo toma el Beato del Manual pseudoagustiniano ${ }^{11}$. Pero es evidente que recoge, aunque la cita no sea plenamente literal, un texto de la obra agustiniana: "Nunca estás pobre y te gozas con los lucros; no eres avaro y exiges usuras" $(1,4,4) 12$.

La segunda se halla en el libro segundo de la obra del Beato y se refiere al octavo de la agustiniana. El texto es el siguiente: "Estaba preso no con la cadena de hierro, sino con la cadena pesada de mi voluntad" $(2,10)$ que se corresponde perfectamente, aunque tampoco aquí con plena literalidad, a este pasaje agustiniano: "Ligado no con hierros extraños, sino por mi férrea voluntad. Poseía mi querer el enemigo, y de él había hecho una cadena con la que me tenía aprisionado" (8,5,10 13). Aquí el Beato menciona al Santo pero no por su nombre, sino mediante el circunloquio: “... un gran siervo vuestro, para dar a entender el tormento que da el tirano y propio querer al que a él obedece". $(2,10)$. Palabras que recogen en síntesis buena parte del mismo libro octavo $(8,4,9-11,27)$.

Aparte de estas dos citas explícitas, aunque no exactamente literales, se pueden detectar otras múltiples referencias, no siempre igual de nítidas, de la obra del Santo en la del Beato. Procederemos por orden progresivo de mayor a menor seguridad.

En el libro segundo hallamos una nueva utilización indiscutible de la obra del Santo. Escribe el Beato: "La virtud de estas palabras soberanas sacó a San Antonio del siglo, y dio con él en un desierto. Éstas obraron con tanta eficacia en nuestro Padre San Agustín, para que no tuviese en nada la retórica, y filosofía, y se hiciese vuestro discípulo, y humillase la cerviz al dulce yugo de la santa fe" $(2,3)$. La primera parte del texto no deja lugar a dudas de que en él Fr. Alonso se hace eco del relato de la conversión $(8,12,29)$ y del abandono de la cátedra de Retórica por parte de Agustín (9,2,2-4). Y, a

11. Manuale 1,1: PL 40, 952.

12. Numquam inops et gaudes lucris; numquam avarus et usuras exigis $(1,4,4)$.

13. Las ediciones señalan el libro noveno, pero se trata de un error. 
su vez, la expresión "humillar la cerviz al ... yugo", de clara resonancia evangélica (Cf. Mt 11,29; Hech 5,10), tiene paralelos, entre otros lugares, en el primer capítulo del libro noveno agustiniano: "Para que yo sometiese la cerviz a tu yugo suave" $(9 ; 1,1)$. Nos encontramos ante una expresión de la que el Obispo de Hipona suele servirse para designar su propia conversión. Un nuevo ejemplo lo tenemos en este otro pasaje: "Tú que reprimiste mi soberbia con tu temor y domaste mi cerviz con tu yugo, el cual llevo ahora y me es dulce, porque así lo prometiste y lo has cumplido" (10,36,58; cf. también $3,5,9 ; 4,15,25 ; 7,7,11)$.

Otros pasajes del Beato tampoco permiten la duda en cuanto a la inspiración agustiniana. Sirva como primera prueba la conclusión del prólogo. Allí escribe: "También declaro mis culpas, porque cuando después de mi vida, si vos lo ordenáredes, esta escritura viniere a manos de algunos fieles, os den gracias y alaben, Señor, por lo bueno y santo, que conmigo obrasteis: y viendo mis faltas, hagan oración por mí, para que goce yo de vuestra vista en el cielo perpetuamente". Texto que evoca aquel otro con que Agustín justifica el ampliar las Confesiones, escribiendo el libro décimo, en modo de referir también el estado presente de su vida: "Me manifestaré a los tales, porque no es pequeño fruto, Señor Dios mío, el que sean muchos los que te den gracias por mí y seas rogado de muchos por mí. Ame en mí el ánimo fraterno lo que enseñas se debe amar y duélase en mí de lo que enseñas se debe doler $(10,4,5)$.

Asimismo en 1,7 leemos: "Riquezas vuestras son los dones que yo he recibido, dulcísimo Jesús, salud del mundo: y obras mías mis culpas y descuidos". Palabras que evocan de inmediato aquellas otras del Obispo de Hipona en el mismo libro y capítulo últimamente citados: "Me manifestaré a esos tales. Respiren en mis bienes, suspiren en mis males. Mis bienes son obras $y$ dones tuyos; mis males son pecados míos y castigos tuyos" $(10,4,5)$.

Aunque con menos claridad, no faltan otros textos en que no es difícil captar resonancias de páginas agustinianas. Así en estas palabras del Beato: "Regid vos mi lengua, para que en tan excelente oficio (de la alabanza) se ejercite, y jamás desmaye", se perciben ecos, quizá un tanto lejanos, de estas otras del Santo Obispo: "Recibe, Señor, el sacrificio de mis Confesiones de mano de mi lengua, que tu formaste y moviste para que confesase tu nombre" $(5,1,1)$.

De igual manera, al amparo de Sal 140,3, se percibe el eco de este texto agustiniano: "Porque todavía no habías puesto guardia a mi boca ni puerta que cerrase mis labios para que mi corazón no declinase a malas palabras" $(5,10,18)$ en este otro de Fr. Alonso: "Poned una puerta de vuestra sagrada mano, y sed vos el portero, para que no se abra sino para bendeciros... $\mathrm{Si}$ 
vos sois la guardia, jamas mi lengua se desmandará jurando ni maldiciendo, ni tocando a fama ajena" $(1,5)$.

Cuando el Beato presenta a su madre María lo hace con las palabras: "Sierva vuestra", que evocan un modo de Agustín de presentarse a sí mismo: Hijo de tu sierva $(2,3,7 ; 5,10,18 ; 9,1,1)$.

Ambos autores han visto sus traslados de residencia como impulsados por la Providencia. Como Agustín confesaba: "También fue obra tuya el que me persuadiesen irme a Roma" $(5,8,14)$, así también Fr. Alonso: "Me guiasteis a Salamanca" $(2,3)$, o "siendo vos el que lo encaminaba, mis padres me enviaron a Toledo" $(2,2)$.

$\mathrm{Al}$ relatar las tentaciones que le incitaban al abandono del propio estado religioso, el Beato atribuye a Cristo la superación de las mismas: “ $\mathrm{O}$ cuántas veces estuve determinado ya de dexar la vida santa que había comenzado! Mas con todos estos combates, Vos, mi Redentor no me dexasteis de vuestra mano" $(2,4)$, como antes lo había hecho el Santo, tentado de abandonar el ministerio y retirarse al desierto: "Aterrado por mis pecados y por el peso enorme de mi miseria, había tratado en mi corazón y pensado huir a la soledad; más tú me lo prohibiste y me tranquilizaste diciendo: Por eso murió Cristo por todos, para que los que viven, ya no vivan para sí, sino para quien murió por ellos (1 Cor 5,15)" (10,43,70).

El relato de la muerte del hermano del Beato $(2,7)$ rememora, aunque a distancia, la muerte del amigo de Agustín (4,4,7ss), resaltando idéntico sentimiento de soledad.

La vinculación entre el hombre y la creación aparece en ambas obras, pero con significado invertido. Mientras en Agustín es el hombre quien se convierte en portavoz de la alabanza de toda la creación $(5,1,1)$, Fr. Alonso pide que toda la creación dé gracias a Dios por él $(1,4)$.

En síntesis, si las palabras del Beato se limitan a señalar que emprende la tarea de escribir sus Confesiones a imitación de su Padre Agustín, su lectura nos demuestra que la obra agustiniana ha dejado testimonios de sí misma que van más allá de la simple identidad de título.

\section{OTRAS RELACIONES}

Ahora es preciso dar un paso adelante consistente en detectar otras formas de relaciones mutuas, ya de identidad, ya de desemejanza. 
1) El término "confesión".

El mismo término "confesión" nos brinda el primer ejemplo de cercanía y de distanciamiento a la vez entre ambas obras. Si bien se puede afirmar sin ningún distingo que la obra agustiniana es toda ella "confesión", no resulta tan fácil aseverar lo mismo de la orozquiana. En efecto, en la primera el mismo término que le da título la domina de principio a fin. En ella se contabilizan 110 presencias del término ( 22 en la forma nominal y 88 en la verbal) ${ }^{14}$, equilibradamente distribuidas a lo largo de toda la obra, dejando la sensación de que en su materialidad se constituye en elemento esencial de la misma. En la segunda, en cambio, sólo se advierten 14 presencias del mismo. Pero más instructivo que el puro dato estadístico, que se podría justificar por la distinta extensión de una y otra obra, es este otro: mientras en la obra agustiniana, todas las presencias, excepto cuatro, se encuadran en un ámbito semántico característico, en la del Beato el caso es notablemente diverso. Basten estos datos: cinco de ellas (prólogo [2], 1,1 [3]) se refieren al sacramento de la reconciliación, significado ausente en la obra agustiniana; dos son simples referencias a la obra misma $(1,2 ; 3,4)$; otras cinco están tomadas en la acepción genérica de reconocer $(2,6 ; 2,7 ; 2,11 ; 3,4 ; 3,9)$, de forma que sólo tres veces el término aparece como confesión de alabanza y del propio pecado (1,2 [2] ${ }^{15}$. A todas luces el término confesión-confesar pierde protagonismo en la obra del religioso agustino, hasta el punto de que, atendiendo a este dato específico, difícilmente podríamos afirmar que la obra sea con propiedad una "confesión". Contrariamente al proceder del Santo, el Beato cambia habitualmente el término por sus equivalentes semánticos.

Se podría pensar en que la lengua no le ofrecía las mismas posibilidades. Pero conviene no olvidar que S. Agustín hubo de imponerse al uso común. En efecto, la acepción "alabar-alabanza" otorgada a confiteri-confessio existía en el latín cristiano de los primeros siglos, especialmente en contextos escriturísticos. Pero si era conocido por las gentes cultas, no era el lenguaje corriente de los cristianos ${ }^{16}$. La prueba nos la da él mismo al afirmar que sus fieles, siempre que oían el término confiteri-confessio comenzaban a golpearse el pecho ${ }^{17}$. Señal inequívoca de que para ellos el término tenía un significado unívoco. Es cierto que no fue él el creador de esa nueva acepción, pero sí que la vulgarizó. El Beato no osó hacer innovaciones.

14. Cf. la relación de todas ellas en L. Verheisen, Eloquentia, 11-21.

15. Con la peculiaridad de que no es el verbo quien propiamente significa una y otra cosa, sino los complementos de que va acompañado.

16. Cf. Enarratio in ps. 117,1: "minus erudita multitudo".

17. Cf. En. in ps. 117, 1; 141,19. 
Veamos ahora el significado preciso del término, al que ya hemos hecho algunas referencias. El significado de confessio en la obra agustiniana ha sido repetidamente estudiado ${ }^{18}$. Todos los autores coinciden en que incluye a la vez el de alabanza y de reconocimiento de los pecados (al que algunos añaden el de confesión de la fe $\left.{ }^{19}\right)^{20}$. Pero conviene no olvidar que esos dos significados fundamentales están enriquecidos por otros secundarios ${ }^{21}$. Los testimonios en favor de uno y otro son innumerables. Pero en ningún modo son totalmente independientes ambos significados, pues la confessio como acto de alabanza incluye como motivo la misericordia por la que Dios perdona los pecados a quien con humildad los reconoce ${ }^{22}$, rasgo que denota la dependencia bíblica ${ }^{23}$. La integración en la obra de ambos es plena y armó-

18. Cf. L. VerheiJen, Eloquentia , 21-82; C. Mohrmann, Considerazioni sulle "Confessioni" di sant'Agostino, en Études sur le latin des chrétiens. T. II: Latin chrétien et médieval, Roma 1961, p. 278ss; J. RATZINGER, Originalität und Überlieferung in Augustins Begriff der Confessio, en Revue des Etudes Augustiniennes 3 (1957) 375-392. Cf. también las introducciones a las ediciones modernas en las distintas lenguas.

19. Cf. C. Mohrmann, Considerazioni, p. 280; P. CourCelle, Recherches sur les Confessions de saint Augustín. Paris 1950, p. 19.

20. Así lo sintetiza L. Verheijen: "En spécifiant de plus près la notion, nous avons ensuite défini confiteri comme: parler à Dieu en toute loyauté, dans la conscience donnée par la Lumière de Dieu que Dieu est le Créateur de tout et le Sauveur de l'humanité; ce qui implique d'un côté la conscience que l'on n'est par soi-même qu'une créature ignorante qui n'a que son péché en propre, mais en même temps de l'autre que, par la bonté de Dieu, l'on est quelque chose et de plus un "illuminé" et un racheté. Et ci-dessus on a montré que l'accent sera, tantôt surtout sur la nullité et les péchés d'Augustin et de autres hommes, tantôt surtout sur la miséricordieuse bonté de Dieu" (Eloquentia, p. 46)

21. Destacamos, ante todo, el de la gratitud: "D'abord la "louange" n'est pas tout à fait la même chose que l'action de grâces. Mais quand Dieu, comme dans les Confessions, est loué pour tout ce qu'il signifie pour la création en général et spécialment pour l'humanité, louange et action de grâces sont si intimement liées que nous n'attacherons pas à cette différence beaucoup d'importance" (L. VERHEIJEN, Eloquentia, p. 36).

22. Enarratio in Ps. 94,4: "Antequam veniat, nos confitendo damnemus quod fecimus, ut ille quod coronet non quod damnet, inveniat. Numquid autem et hoc non pertinet ad laudem dei, quando confiteris peccata tua? Imo vero maxime pertinet ad laudem dei. Quare maxime pertinet ad laudem dei? Quia tanto amplius laudatur medicus, quanto plus desperabatur aegrotus". Así se expresa C. Mohrmann: "Non seulement que le titre de Confessiones s'appuie sur le double sens de confessio, c.-à-d. la confessio laudis et la confessio peccatorum, mais plusieurs des passages les plus sublimes de ce libre admirable perdent leur sens, quand on ne se représente pas constamment le sens double de confiteri. Un tel jeu subtil, dans le quel les deux sens du mot se relayent et chevauchent presque sans qu'on s'en aperçoive nous offre l'exorde du cinquième livre des Confessions" (Quelques observations linguistiques à propos de la nouvelle version latine du psautier, en Etudes, T. III, p. 209. Cf. L. VERHEIJEN, Eloquentia, p. 47).

23. "The linking of "confession of sin" and "glorification of God", so inexpected and paradoxal for the classical mind, and only explainable by the Old Testament Jewish thought, received its fullest literary exploitation in St. Augustine's Confessions" (C. MoHRMANN, Linguistic Problems in the Early Christian Church, en Etudes, T. III, 185). 
nica, sin fisuras de ningún tipo. En la combinación de uno y otro significado, la obra agustiniana es toda ella, como ya indicamos, una auténtica confesión.

En las Confesiones del Beato se hallan presentes, y explícitamente admitidos, tanto el significado de alabanza como el de reconocimiento del propio pecado. Así lo expresa él: "Dos maneras, Señor mío, hay de confesión, según el rey David nos enseña, y la divina Escritura en diversos lugares declara: una confesión es de alabanzas, que se dan a vuestra divina Majestad, porque no solamente sois bueno, mas sois la misma bondad" $(1,2)$. El discurso queda desequilibrado porque el Beato parece olvidarse de formular la otra manera de confesión, es decir, el reconocimiento del propio pecado. El olvido se refiere únicamente a la explicitación formal, pues es a él al que ha recurrido en el capítulo anterior.

Pero a pesar de esta coincidencia genérica en cuanto al doble significado del término "confesión", ambos escritos se distancian no poco entre sí al respecto. En la obra orozquiana falta en primer lugar la riqueza de reflexiones y de situaciones personales que estimulan tanto la alabanza como el arrepentimiento. En segundo lugar se echa de menos el equilibrio y armonía entre uno y otro significado que se advierte en la agustiniana. De hecho, el triple acceso a la obra, es decir, el título, el prólogo y el primer capítulo hacen pensar en el predominio, cercano a la exclusividad, de la "confesión" como reconocimiento del propio pecado, e incluso con marcado carácter sacramental, ajeno éste a la obra agustiniana. Sigamos ese mismo orden.

Ya el título, leído en su integridad, orienta al lector en el sentido de identificar la confesión con el reconocimiento del pecado. Reza así: "Libro de las Confesiones de este pecador". Esta primera impresión se confirma de inmediato con la lectura del prólogo. En él señala que, siendo pecador, quiere imitar la "grande humildad de vuestro gran siervo, mi Padre San Agustín que hizo trece libros de sus confesiones para gloria vuestra y ejemplo de los cristianos". El hacer del acto de escribir las Confesiones una manifestación de humildad resulta, en el contexto, signo inequívoco de la vinculación entre confesión y pecado. Y más cuando añade que lo hizo para ejemplo de los cristianos "que de voluntad vayan a la confesión sacramental a decir sus pecados en secreto a un Vicario de vuestra piadosa mano dado, para que les absuelva de ellos". Al concluir que es tan poderoso el amor del Señor "que aún hay quien se acusa públicamente de sus culpas, y con su mano las escribe", queda clara la vinculación de la "confesión" con el pecado y la culpa.

Lo mismo cabe deducir de la lectura del primer capítulo. Lo introduce con la cita de Sal 31,5: Determiné de confessar contra mí mi pecado, y Vos, Señor, perdonasteis la maldad de mi culpa, palabras de David que él reconoce que se lleva aplicando, para consuelo propio, durante muchos años. Y el 
primer atributo divino que trae a colación es el de su clemencia y, luego, su misericordia. Hombre y Dios aparecen como ofensor y ofendido, a diferencia del comienzo de la obra agustiniana en que son presentados como creador y criatura. Acto seguido menciona la confesión sacramental, para continuar encareciendo la excelencia del perdón divino, tan distinto del humano. El ejemplo bíblico que aduce es el de Zaqueo, "a cuya mesa os sentasteis el día que le perdonasteis los pecados", y el de Mateo. El resultado a que llega es: "con tales palabras despierto y con tales prendas confiado, determiné escribir mis pecados en este libro, habiéndolos confesado sacramentalmente muchas veces con vuestro favor".

Es tan fuerte la insistencia en la "confesión" del pecado en esta triple entrada a la obra que hace pensar a quien tiene un mínimo conocimiento de la obra agustiniana que el imitador no ha calado en la riqueza del significado del término "confesión" usado en la obra prototipo. Y hasta conduce a que se desvirtúen otros elementos del prólogo que orientan hacia el significado de alabanza por los bienes otorgados por Dios. Allí se lee también: "Y sepan los dones y mercedes que su alma recibió", al lado de las culpas que cometió. Pasaje donde afirma asimismo: "También os declaro mis culpas, porque cuando después de mi vida, si vos lo ordenáredes, esta escritura viniere a manos de algunos fieles, os den gracias y alaben, Señor, por lo bueno y santo que conmigo obrasteis". Aquí el primer significado de la confesión aparece en función del segundo: declara sus culpas para que sean motivo de alabanza a Dios, al poner de relieve su obra en el Beato.

Es justamente la idea que se repite al final del primer capítulo. En efecto, si se decidió a escribir sus pecados fue con la finalidad de que "si algunos los leyeren, alaben vuestra gracia y misericordia". Este significado de alabanza es el que va a prevalecer, con diferencia, en el resto de la obra, no obstante que formule sus propósitos de esta manera: "comenzar alabando vuestra bondad, y misericordia, recontando vuestros dones conforme al discurso de mi vida, para también adelante confesar mis pecados". Con estas palabras parece exponer el plan de la obra, a realizar en dos momentos: referir primero los dones de Dios como motivo de alabanza, y luego confesar los pecados. Dos partes que no tienen que ser necesariamente equilibradas. Sea o no sea así, sólo muy parcialmente responde el escrito a él. El canto de alabanza es el que prevalece en la obra, en la que el reconocimiento del pecado tiene una presencia verdaderamente insignificante, y no más "adelante", sino al hilo del discurso. En este sentido la obra desilusionaría aún más que la agustiniana a quienes fuesen a leerla esperando encontrar en ella una relación de pecados. Hasta el punto que, a una lectura distante, a quien no conoce la realidad de la vida espiritual, puede dar la impresión de ser un tanto hipócri- 
ta el apelativo de pecador que se aplica ya en el mismo título de la obra. La diferencia es notable respecto al obispo de Hipona, quien con su obra logró vender a la posteridad la idea de que fue un gran pecador; idea que ha prevalecido hasta nuestros días en la concepción popular.

En efecto, dejando de lado formulaciones genéricas de culpabilidad, no excesivas por otra parte ${ }^{24}$, si nuestra lectura ha sido lo suficientemente atenta, los únicos pecados específicos que menciona son los de ingratitud, de lengua, de orgullo, de negligencia en el servir al hermano enfermo y de pensamiento. El primero por el que pide perdón es el de ingratitud: "Suplícoos, Señor, que perdonéis mi ingratitud, y negligencia en serviros, estando tan obligado de todas partes" (Prol.). También: "O gloria mía, perdonadme que he sido ingrato, no alabando a vuestra majestad" $(1,4)$. De los pecados de lengua escribe: "O dulce Jesús, o salud de mi alma, ¡cuántas veces os ofendí con la lengua, que para alabaros y dar siempre gracias me disteis! Perdonadme y dadme virtud, para que jamás os ofenda" $(1,5)$. También la existencia del orgullo le da motivo para suplicar perdón: "Perdonadme, gloria mía, todos mis humos de altivez, por reverencia de tan grande humildad. Plantad en mi esta virtud celestial, virtud y guarda de todas las virtudes" $(1,7)$. Perdón que solicita también por un comportamiento concreto: "Perdonadme la negligencia que en servir a este vuestro siervo tuve en aquella enfermedad tan larga y penosa" $(2,7)$. Por último, las faltas de pensamiento: “... aunque soy de ochenta años, no hay edad segura en tanto que vive la carne; mas porque el combate de pensamientos suele ser importuno, y peligroso en cualquiera manera, que Vos sabéis, mejor que yo, no haber resistido presta y fuertemente, me acuso, y me pesa, y por vuestra gran misericordia perdonadme" $(2,9)$. A todo ello cabe añadir todavía las dificultades con la obediencia, positivamente superadas: “... y si algunas veces, ordenándolo vuestros ministros, sentía pesadumbre de aceptar cargos, y en mudanza de largos caminos, al fin, peleando con mi voluntad, se sujetaba al yugo de la obediencia" $(2,10)$.

Sin duda se trata de actitudes o hechos concretos, contrarios a la santidad del cristiano. Ciertamente están presentes en la obra, pero carecen de entidad narrativa y no permiten entrar a demasiadas profundidades del alma de su autor. Se trata más bien de desahogos espirituales, inequívocamente sinceros, pero cercanos al tópico y con poco peso específico en el relato. Sin duda, la distancia respecto a la obra agustiniana es lógicamente tanta cuanta existe entre ambas historias religiosas, y en las respectivas capacidades de autoanálisis.

24. Hace referencia a sus culpas $(1,6)$, a sus culpas y descuido $(1,7)$, a su flaqueza $(2,11)$, a haber ofendido a Dios $(2,13)$, y a faltas $(3,3)$. 
En síntesis, aunque ambas obras se hallan unidas por el acuerdo semántico, aunque con matizaciones, respecto al término confesión, se distancian notablemente en la proporcionalidad de las presencias de uno y otro significado. Mientras del sentimiento de alabanza-gratitud hacia el Señor se contabilizan más de ochenta expresiones, a los que hay que añadir las once de bendición, dos de engrandecimiento y una de glorificación, el sentimiento que brota de un corazón que se sabe pecador queda reducido a lo antes indicado. Aunque más valor que a la presencia cuantitativa hay que asignárselo a la cualitativa. En este sentido el motivo de la alabanza tiene mucho más peso en el cuerpo de la exposición; el de arrepentimiento aparece siempre como un epígono del anterior.

\section{2) La estructura externa}

La distinta extensión de ambas obras no requiere particular consideración, por tratarse de un elemento puramente material. Pero, aunque dejemos de lado el número de trece libros de las Confesiones agustinianas, vale la pena prestar atención a la indiscutida división tripartita de la obra, correspondiente a los libros I-IX, X y XI-XIII respectivamente, porque tripartita es también la división establecida por Fr. Alonso, en este caso coincidente con los libros de la obra. Y aquí se acaba prácticamente toda la coincidencia.

En primer lugar, son diversos los criterios sobre los que se establece la división. En el caso de Agustín, dejando aparte el problema de la unidad interna de la obra ${ }^{25}$, hallamos un criterio personal: un pasado, con las etapas de alejamiento de Dios y de retorno a él (l. I-IX), y luego un presente en el que considera dos aspectos: el aspecto moral (l. X) y el aspecto intelectual, centrado en el conocimiento de la Escritura (1. XI-XIII). En el del Beato Alonso los criterios son "intencionalmente" teológicos. Es él mismo quien lo indica con estas palabras: "Va dividida en tres libros para honra y gloria de la Santísima Trinidad". Hemos entrecomillado el término "intencionalmente" porque entendemos que es la única manera de aceptar como verdadera su afirmación: quiso componer los tres libros en homenaje a las tres Personas de la Trinidad. De hecho, sin embargo, la referencia a la Trinidad se acaba en el número ternario de libros. Nada hay en la obra, al menos no lo hemos percibido, que nos permita establecer una relación concreta de ellos con las distintas personas divinas. Dicha declaración, ya en el mismo pórtico del libro, podía hacer pensar al lector en algún tipo de vinculación de cada

25. Problema nunca solucionado a gusto de todos. Cf. A. Solignac en la Introducción a las Confesiones en la edición de la Bibliotèque Augustinienne 13, p. 19ss. 
una de ellas a cada uno de los libros, pero no es ese el caso. La espiritualidad que traspira en ningún modo es trinitaria, sino, como veremos, totalmente cristocéntrica.

Desde el punto de vista del contenido real el criterio de división ya no es tan personal como en las Confesiones agustinianas. Le cuadra a él, pero como uno entre muchos. El primer libro se ocupa del hombre que por el bautismo acaba convirtiéndose en cristiano 26; el segundo del cristiano que sigue el camino de la perfección en la vida religiosa; el tercero dedica los capítulos iniciales a Jesucristo para ponderar luego otros beneficios del Señor. Se advierte cómo este tercer libro rompe el esquema cronológicoespiritual que representan los dos anteriores.

Cada autor, pues, sigue su camino particular. La gran diferencia está en que Agustín, personalidad irrepetible, ha adoptado una división, cual traje hecho a la medida para sí mismo, mientras que el Beato ha adoptado otra que deja pensar más en un uniforme que puede compartir con otros muchos. Además, para seguir con el símil, el Santo se mostró mejor sastre que el Beato.

Al pasar ahora a los capítulos, respecto a la obra agustiniana, se impone la aclaración siguiente: la división actual de capítulos no procede directamente del Santo, a diferencia de los de las Confesiones del Beato. En la obra de Fr. Alonso éstos tienen una estructura muy uniforme. Por de pronto todos tienen un título que da el tema. Además, todos, sin excepción, comienzan con un versillo bíblico, tomado ya del Antiguo ya del Nuevo Testamento, que abre las puertas al desarrollo del tema señalado en el título. Sigue una reflexión ponderando la obra graciosa y misericordiosa de Dios sobre los hombres, que estimula la alabanza y la gratitud. Dentro de esa historia de amor de Dios hacia los hombres, introduce, como un caso más, la suya particular, de la que nos aporta abundantes datos. Concluye con la expresión de otros sentimientos que brotan al hilo de las consideraciones anteriores, con frecuencia en forma de oración de súplica, entre la que aparece la de súplica de perdón, que ya mencionamos. Demasiado fiel a su esquema, se echa de menos en su obra la espontaneidad, que se traduce luego en riqueza de situaciones y perspectivas, que se percibe en la obra del Obispo de Hipona. Volviendo el símil anterior, también a este respecto, para referirnos al Beato podemos hablar de uniforme, mientras que la realidad agustiniana la expresa mejor el traje a medida. Esto no implica excluir de Agustín todo esquema en el tratamiento de las diversas unidades temáticas, -mejor que capítulos-.

26. Es aquí donde el Beato más coincide, a nivel de contenido, con el Santo: al narrar la obra creadora y conservadora del ser del hombre por parte de Dios. 
Pero aunque se pueda hablar del esquema: relato, reflexión, oración conclusiva, es tanta la variedad en la forma de presentar el relato; son tantas las direcciones de la reflexión, y las formas de oración que sigue siendo válido lo que afirmamos. En todo caso, él se siente libre incluso frente a dicho esquema, que no siempre podrá aplicar, sobre todo en la segunda y tercera parte de la obra. En general se puede mantener que las diferencia al respecto entre los dos autores es la traducción en estructura de la mayor riqueza de pensamiento y mayor dominio de la lengua por parte de Agustín.

\section{3) Espiritualidad.}

No es nuestro intento entrar en profundidad en la espiritualidad de uno y otro escrito. Siendo tan rica, sobre todo por lo que se refiere a la obra agustiniana, no se la puede encerrar en el reducido marco de este apartado. Nos limitamos a presentar dos simples apuntes, suficientes, en un estudio comparativo, para mostrar la neta diferencia entre las dos obras. Estos dos apuntes se refieren respectivamente a las fuentes de la espiritualidad y a un rasgo definitorio de la misma. Dicho esquemáticamente: mientras el Santo bebe sobre todo en la Escritura y particularmente en los Salmos, el Beato no; mientras la obra del Santo del siglo cuarto es marcadamente teocéntrica, la del Beato del siglo de oro español es señaladamente cristocéntrica.

\section{a) La fuente de la espiritualidad.}

¿Cuál es la fuente de la que, con preferencia a las demás, bebe Agustín en sus Confesiones? La respuesta no admite vacilaciones: es la Escritura. De ella es deudora hasta en rasgos de carácter literario que le son peculiares ${ }^{27}$. Pero no todas las partes de la Escritura tienen el mismo peso al respecto. Hay una que sobresale, con diferencia, sobre las demás: el salterio. El acuerdo entre los estudiosos es prácticamente unánime. Los salmos arrojan una luz poderosa sobre esta obra agustiniana. Sus versillos forman como la estructura que soporta todo el edificio 28. Si Agustín se manifiesta en la obra sobre todo a través de imágenes, se debe a que detrás está la poesía de los salmos ${ }^{29}$. Pero éstos no se limitan a ofrecerle el lenguaje para expresar sus

27. Cf. L. VerheIJen, Eloquentia, cap. II: La forme, pp. 83-141. C. MorhmanN, Considerazioni, pp. 318.

28. Cf. N.G. Knauer, Die Psalmenzitate in Augustins Konfessionen. Göttingen 1955; Peregrinatio animae. Zur Frage der Einheit der augustinischen Konfessionen, en Hermes 85 (1957-58) 216-248.

29. "Dappertutto e sempre Agostino ama le immagini, ma in nessun luogo egli sfrutta a tal punto questo procedimento come nelle Confessioni... Non si tratta di una semplice figura di stile. L'immagine vi è intimamente legata alle risonanze religiose e, in questo impiego cos- 
sentimientos, sino que llegan hasta inspirarle abundancia de sus sentimientos. La forma de proceder del Santo en esta obra supera con mucho la técnica habitual de la cita, en que se explicita la dependencia. Sólo una vez, y en relato histórico, señala Agustín que los salmos son de David $(9,4,8)$, creyendo que lo son en su totalidad. En el resto de los casos, innumerables, aunque se sirve de su lenguaje, no menciona para nada al Rey poeta. Hasta tal punto se ha identificado con su forma de expresarse y sus sentimientos que los considera propios y no ya de David.

Distinto es el caso del Beato. También la Escritura ocupa en sus Confesiones un lugar digno de mención. De los textos bíblicos citados, los tomados del Salterio tienen una presencia discreta. Incluso aparecen, sobre todo en el primer libro, abriendo varios capítulos y orientando ya el desarrollo de los mismos. Pero no se puede afirmar que tengan significado alguno en la estructura interna de la obra, ni que hayan dejado sus huellas en el aspecto literario ${ }^{30}$. Tampoco que el Beato se alimente especialmente de ellos. En todo caso no en el mismo nivel que Agustín. Los usa con la técnica habitual de la cita, es decir, reconociendo explícitamente la dependencia. Si se nos permite hablar así, los salmos siguen siendo de David. No se puede afirmar que sus sentimientos, más contenidos y menos numerosos que los del Obispo de Hipona, procedan del salterio; más bien derivan directamente de Agustín, a quien se propuso imitar. Sólo es preciso advertir cuán pocas veces cita salmos de alabanza, no obstante que el sentimiento de alabanza sea preponderante.

En su obra Agustín va a la par con el autor de los salmos en los que es la obra de Dios en la creación y en la historia propia la que suscita los sentimientos; una y otra son el punto de arranque para elevarse hacia Dios. En la del Beato, en cambio, cuya reflexión es más de "escuela" que de vida, aunque integre la vida en ella, dicha elevación surge preferentemente de la consideración de la acción salvadora de Cristo. Eso explica el notable cuño metafísico de la obra antigua, apenas presente de la moderna, sin perderse

tante e abbbondante de immagini, parecchi elementi si incontrano: ... ma soprattutto e inanzitutto l'influenza della poesia biblica. Si può veramente parlare di una iniziazione di Agostino alle maniere espressive della poesia semitica che si manifesta tra l'altro nell'impiego dell'immagine come linguaggio privileggiato della vita spirituale. E qui noi ci troviamo davanti ad uno degli elementi essenziali e tipico dello stile delle Confessioni. La lettura assidua della Bibbia ha mostrato a Sant'Agostino che il dialogo di Dio e dell'uomo può svolgersi per mezzo del mondo sensibile, nonostante certe teorie neoplatoniche" (C. MOHRMANN, Considerazioni, p. 319). Cf. también J. FonTAINE, Sens et valeur des images dans les "Confessions", en Augustinus Magister I, 117-126.

30. Dejamos de lado la cita en sí misma, que puede reflejar el original hebreo del que pudo traducirlo directamente el Beato. 
fuera del tiempo. En efecto, una y otra están enraízadas en la historia, pero de distinto modo. En la agustiniana, la historia va asociada sobre todo al elemento humano, a Agustín mismo; en la orozquiana va unida sobre todo a Cristo, que se hace presente en medio de los hombres. Y esto nos lleva de la mano al segundo aspecto, antes mencionado.

\section{b) Teocentrismo-Cristocentrismo}

Las distintas espiritualidades cristianas pueden establecerse sobre criterios diferentes. Si los diversos modelos de espiritualidad se reducen a las distintas maneras de mantener el diálogo religioso y vital del hombre con Dios, un principio diferenciador estará en los distintos modos de "entender" la persona con quien el hombre dialoga. La teología cristiana, con su concepción del Dios trino, deja abiertas las puertas a varias posibilidades, entre otras la teocéntrica, la cristocéntrica y la pneumatocéntrica. Desde este punto de vista, ¿qué relaciones pueden establecerse entre las obras que nos ocupan?

Un camino directo y rápido para entrar en la concepción que ambos autores tienen de su interlocutor divino es, a nuestro parecer, el de examinar los títulos con que uno y otro se dirigen a él.

El mismo significado del término que da título a nuestras obras nos pone ya de entrada en contexto de oración. Efectivamente, una y otra fueron concebidas y realizadas como plegaria. Ni el Santo ni el Beato se limitaron a escribir en presencia de Dios; fueron más lejos, hasta hacer de su escrito un diálogo ininterrumpido que tiene a Dios como único interlocutor directo ${ }^{31}$, de principio a fin.

$\mathrm{Si}$ algo caracteriza a ambos escritos en cuanto plegaria es el recurso continuo a la invocación, natural cuando se da preferencia al lenguaje del corazón. Dios es objeto de invocaciones constantes. El orante recurre a los títulos que adornan, ensalzan $\mathrm{u}$ "obligan" a aquel con quien dialoga. En efecto, unas veces tienen una función de reconocimiento de su dignidad: es ya una captatio benevolentiae que permite abrigar esperanzas de éxito para la propia súplica. Otras puede servir de "recordatorio" de los lazos existentes entre ambas partes, nuevo camino abierto para lograr lo que se pretende. Por eso el lenguaje de la invocación nos parece el lugar apropiado para ver cómo

31. Si nos expresamos así es porque no olvidamos que, a otro nivel, tanto el Santo como el Beato, tienen como interlocutores a los hombres. Para las Confesiones de Agustín, cf. 2,3,5 y 10,3,4-5,6; para las del Beato, cf. el prólogo. 
conciben uno y otro autor al Dios con quien dialogan. Y a partir de ahí definir las espiritualidades respectivas.

La riqueza en fórmulas de invocación es algo que hermana a úno y otro escrito ${ }^{32}$. Pero su caminar juntos no va mucho más lejos. Al lado de coincidencias evidentes, existen notables divergencias que se extienden desde el número de títulos hasta la frecuencia en su uso, pasando por el sujeto al que se aplican ${ }^{33}$. El cuadro sinóptico nos permitirá un primer acercamiento a la realidad, que luego someteremos a un ligero examen.

\section{Agustín ${ }^{34} \quad$ Orozco $^{35}$}

Aguila poderosa

Alabanza

$1^{37}$
$1^{38}$
$1^{39}$
$1^{40}$
$1^{41}$
442
143
$2^{44}$

32. En la obra agustiniana se cuentan poco más de quinientas invocaciones, aisladas o agrupadas. Cfr. S.Pôque, L'invocation de Dieu dans les Confessions, en Augustiniana 41 (1991) (= Melanges T.J. Van Bavel, II) p. 927. En la orozquiana hemos contabilizado 236.

33. Partiendo de que siempre se aplican a Dios, se trata de ver a qué persona divina en concreto.

34. En el elenco de términos que ponemos a continuación sólo mencionamos aquellos que aparecen con carácter invocativo, dejando de lado aquellos otros de carácter declarativo. Entre los primeros incluimos también los que aparecen en aposición, aunque no sea en vocativo. Los adjetivos, aunque sean sustantivados, sólo los añadimos en nota cuando aparece el término abstracto correspondiente. Mantenemos, sin embargo, Omnipotente y Omnitenens.

35. Nos limitamos a señalar el lugar. Sólo cuando hay variantes en la forma la explicitamos.

36. 3,7

37. 9,13,35 (Laus mea et vita mea)

38. 11,29,39 (Tu solacium meum)

39. 10,29,40 (O amor qui semper ardes).

40. 11,13,15 (Caeli et terrae artificem).

41. 1,9,14 (Auxilium... meum)

42. 7,7,11 (Adiutor meus); 8,6,13 (Adiutor meus et redemptor meus); 9,1,1 (Adiutor meus et redemptor meus); 11,27,34 (Deus adiutor meus).

43. 9,1,1 (Claritati meae, et divitiis meis et saluti meae).

44. 7,10.16 (O vera caritas); 10,29,40 (Caritas, Deus meus). 


$\begin{array}{lll}\text { Clemencia } & & 11^{45} \\ \text { Confianza } & 146 & \\ \text { Creador } & 18^{47} & 10^{48} \\ \text { Decoro } & 1^{49} & \\ \text { Defensor } & & 150 \\ \text { Descanso } & 151 & \\ \text { Dios } & 331^{52} & 2953 \\ \text { Dulcedumbre } & & 154 \\ \text { Dulzura } & 555 & \\ \text { Esperanza } & 456 & 357 \\ \text { Eternidad } & 158 & \\ \text { Excelsitud } & 159 & \\ \text { Fortaleza } & 160 & \end{array}$

45. 2,1 (O clemencia divina)

46. 1,20,31 (Dulcedo mea, et honor meus, et fiducia mea, Deus meus).

47. 1,10,16 (Domine Deus, ordinator et creator omnium rerum naturalium); $2,6,12$ (Creator omnium, deus bone); 3,8,16 (Verus creator et rector universitatis); 4,10,15 (Deus, creator omnium); 5,5,8 (Domine, creator omnium); 5,10,19 (Domine coeli et terrae, creator omnium visibilium et invisibilium); 8,1,2 (Te, creatorem nostrum); 9,6,14 (Domine deus meus, creator omnium); 9,12,31 (Deus, creator omnium); 10,34,52 (Deus creator omnium); 10,35,57 ( $\mathrm{Te}$, creatorem mirificum et ordinatorem omnium rerum); 11,12,14 (Deus noster, omnis creaturae creatorem); 13,5,6 (creator universae creaturae); 13,22,32 (Domine Deus noster, creator noster); 11,13,15 (Omnipotentem et omnicreantem et omnitenentem); 1,22,31 (Domine, tibi, excellentissimo atque optimo conditori et rectori universitatis); 11,4,6 (Tu, conditor eorum); 11,31,41 (Tu, conditor universitatis, conditor animarum et corporum).

48. Prol. (Criador y salvador); 1,1 (criador de todas las cosas); 1,2 (Criador y Redentor); 1,3 (Poderoso criador); 1,3; 2,7; 3,3 (Criador y Señor); 1,5 (Padre mío y criador); 1,6 (Criador del mundo); 1,7 (Criador de esta misma tierra).

49. 10,34,53 (Deus meus et decus meum).

50. 2,12 (O defensor mío).

51. 12,26,36 (Celsitudo humilitatis meae et requies laboris mei).

52. El dato, que tomamos de S.Pôque (L'invocation p. 927, n. 1.) se refiere en conjunto a Domine, Deus y Domine Deus.

53. 1,1; 3,6 (Dios y señor mío); 1,1 [2]; 3,6; 3,9 (Dios y Gloria mía); 1 ,1 (Dios de mi corazón); 1,4 [2]; 1,7;1,9 [2]; 2,1;2,5 [2]; 2,6;2,10;2,12; 3,4; 3,5 (Dios mío); 1,6 (Gloria mía y Dios mío); 1,8 (Dios y señor de mi alma); 2,7; 3,3; 3,5 (Mi Dios); 3,1 (Dios de mi alma); 3,2 (Rey Mío y Dios mío); 3,3 (Dios omnipotente); 3,7 (Dios y esperanza mía)

54. 2,9 (Dulcedumbre infinita)

-55. 1,4,4 (Deus meus, vita mea, dulcedo mea sancta); 1,6,9 (Dulcedo mea, deus meus); 1,20,31 (Dulcedo mea, et honor meus, et fiducia mea, Deus meus); 2,1,1 (Dulcedo non fallax, dulcedó felix et secura). También 3,8,16 (deus altissime et dulcissime).

56 4,4,11 (Spes mea); 5,8,14 (Spes mea et portio mea); 6,1,1 (Spes mea a iuventute mea); 11,18,23 (Spes mea).

57. 3,7 (Dios y esperanza mía); 3,8 (Esperanza mía); 3,9 (O esperanza mía).

58. 7,10,16 (O cara aeternitas).

59. $12,26,36$ (Celsitudo humilitatis meae).

60. 1,3 (Virtud y fortaleza mía). 
Fuente

Gloria

Hermosura

Hijo

Honor

Iluminación

Iluminador

Jesús (-Cristo)

Juez

Llamador

Luz

Maestro

Majestad

Mar
761

$12^{62}$

563

164

165

166

367

268

669

170

171

$16^{72}$

273

61. 3,8,16 (Fons vitae); 4,4,7 (Deus ultionum et fons misericordiarum); 6,1,1 (Fons misericordiarum); 6,16,26 (Fons misericordiarum); 9,9,23 (Fontis vitae); 12,30,41 (Te Deum nostrum, fontem veritatis); 13,16,19 (Fons vitae).

62. Prol (Rey y gloria mía); 1,1 [2]; 3,6; 3,9 (Dios y gloria mía); 1,2 (Gloria de los ángeles); 1,$3 ; 1,4 ; 1,7$ (Gloria mía); 1,6 (Gloria mía y Dios mío); 1,8 (Gloria mía y todo mi bien); 2,7 (Señor y gloria mía). A añadir 1,1;2,5; 2,9 [2]; 3,1; 3,5 (Rey de gloria);

63. 3,6,10 (Pulchritudo pulchrorum omnium); 10,27,38 (Pulchritudo tam antiqua et tam nova). A estos dos usos del sustantivo, hay que añadir otros tres usos del adjetivo sustantivado: 1,4,4 (pulcherrime); 2,6,12 (pulcherrime omnium); 1,7,12 (formosissime).

64. 2,10 (Hijo del Padre eterno).

65. 1,20,31 (Dulcedo mea, et honor meus et fiducia mea).

66. 10,23,33 (Qui veritas es, illuminatio mea).

67. 10,31,46 (Te, deo meo, magistro meo, pulsatori aurium mearum, inlustratori cordis mei); 12,11,11 (inhabitatore te atque inlustratori suo); 12,16,23 (te... inlustratorem).

68. 1,11,17 (Te, Domine Iesu); 9,1,1 (Christe Iesu, adiutor meus et redemptor meus).

69. Prol. (Criador y Salvador, Cristo Jesús); 1,2 (O Jesús); 1,5 (O dulce Jesús); 1,7 (Dulcísimo Jesús, salud del mundo); 3,1 (O mi bien Jesús); 3,6 (O Jesús dulcísimo); 3,8 (Mi salvador Jesucristo).

70. $12,25,35$ (Iudex optime).

71. $10,31,46$ (Tibi, .... pulsatori aurium mearum).

72. 1,13,21 (Deus, lumen cordis mei et panis intus oris mei); 3,4,8 (Scis tu, lumen cordis mei); 10,17,26 (Dulce lumen); 11,19,25 (Dulce lumen oculorum meorum); 12,10,10 (O veritas, lumen cordis mei); 12,18,27 (Deus meus, lumen oculorum meorum in occulto); 13,6,7 (O lumen veridicum); 13,23,36 (Lumen meum, veritas); 10,34,52 (O lux, quam videbat Tobias); 11,2,2 (Domine Deus meus, lux caecorum et virtus infirmorum statimque lux videntium et virtus fortium); 11,11,13 (O Sapientia dei, lux mentium); 11,15,18 (Domine Deus, lux mea); 11,23,30 (Lux, veritas); 12,18,37 (Lux omnium veridicarum mentium). Cf. también 8,10,22 (A te, vero lumine inluminante omnem hominem); 13,2,3 (Aversi a te, nostro lumine).

73. 9,9,21 (Te, magistro intimo); 10,31,46 (Te, deo meo, magistro meo, pulsatori aurium mearum, inlustratori cordis mei).

74. 1,3 (Majestad soberana); 2,13 (Soberana Majestad); 3,2 (O majestad infinita).

75. 1,5 (Mar profundo de misericordia). 


$\begin{array}{lll}\text { Médico } & 2^{76} & \\ \text { Misericordia } & 977 & \\ \text { Moderador } & 178 & \\ \text { Omnipotente } & 379 & \\ \text { Omnitenens } & 2^{80} & 183 \\ \text { Ordenador } & 2^{81} & \\ \text { Padre } & 1882 & 185 \\ \text { Pan } & 184 & 186 \\ \text { Piélago de amor } & & \\ \text { Poder Soberano } & & 188 \\ \text { Porción } & 187 & \\ \text { Protector } & & \\ \text { Rector } & 489 & \end{array}$

76. 10,3,4 (Medice meus intime). También 10,38,39 (Medicus es, aeger sum).

77. 3,1,1 (Deus meus, misericordia mea); 3,3,5 (O tu praegrandis misericordia mea, Deus meus); 4,4,7 (Deus ultionum et fons misericordiarum); 5,9,17 (Deus misericordiarum); 6,1,1 (Fons misericordiarum); 6,16,26 (Fons misericordiarum); 9,9,21 (Deus meus, misericordia mea); 12,16,23 (Deus meus, misericordia mea); 13,1,1 (Deus meus, misericordia mea). Cf. también 1,4,4 (Misericordiosissime); 1,6,9 (Misericors misero tuo); 1,18,28 (Domine misericors); 9,1,1 (Domine, bonus et misericors).

78. 7,6,10 (Iustissime moderator universitatis).

79. 3,11,19 (O tu bone omnipotens); 4,15,24 (Omnipotens); 10,4,6 (Tu omnipotens). Aparece junto a Deus en $1,4,4 ; 5,10,18 ; 10,30,42 ; 12,7,7$.

80. 7,15,21 (Tu es omnitenens); 11,13,15 (Omnipotentem, omnicreantem et omnitenentem).

81. 1,10,16 (Domine Deus, ordinator et creator omnium rerum naturalium, peccatorum autem tantum ordinator); 10,35,57 (Te, creatorem mirificum et ordinatorem omnium rerum).

82. 1,18,28 (Dulcis pater); 3,6,10 (Mi pater summe bone, pulchritudo omnium pulchrorum); 8,3,6 (Misericors pater); 9,4,9 (Pater); 9,12,32 (Pater orphanorum); 9,12,33 (Patrem omnium fratrum Christi); 9,13,27 (Patre); 10,31,46 (Pater bone); 10,43,69 (Pater bone); 11,2,4 (Pater); 11,17,22 (Pater); 11,22,28 (Domine Deus meus, bone pater); 11,22,28 (Pater); 11,29,39 (Domine, pater meus); 13,5,6 (Pater); 13,12,13 (Pater, et Fili et Spiritu Sancte); 13,15,18 (Pater bone); 13,24,36 (Pater pietatis). A añadir 1,11,18 (Illa sategebat ut tu mihi pater esses) y 10,4,6 (Sed vivit semper pater meus et idoneus est mihi tutor meus). Adviértase que sólo en un texto $(13,12,13)$ el término Padre aparece en contexto trinitario; todas las demás Dios aparece como padre de Agustín.

83. 1,1; 1,6; 2,11 (Padre de las misericordias); 1,3 (Padre de la misericordia); 1,5; 1,9 [2] (Padre piadosísimo); 1,5 (Padre mío y criador); 2,4 (Señor piadoso y padre de misericordia); 2,12 (Padre de piedad); 2,13 (Misericordioso Padre).

84. 1,13,21 (Panis oris intus animae meae).

85. 1,1 (Piélago de amor sin suelo).

86. 3,5 (Poder soberano y Señor universal).

87. $5,8,14$ (Spes mea et portio mea in terra viventium).

88. 1,3 (Señor y protector mío).

89. 1,20,31 (Tibi excellentissimo atque optimo conditori et rectori universitatis); $3,8,16$ (Unus verus creator et rector universitatis); 9,8,18 (Rector caelitum et terrenorum); 9,12,32 (Polique rector). 


$\begin{array}{lll}\text { Redentor } & 2^{90} & 12^{91} \\ \text { Refugio } & 2^{92} & \\ \text { Rey } & 393 & 2794 \\ \text { Riqueza } & 195 & \\ \text { Sabiduría } & 196 & 2^{97} \\ \text { Salud } & 498 & 5^{99} \\ \text { Salvador } & & 12^{100} \\ \text { Sanador } & 1101 & \\ \text { Señor }{ }^{102} & & 91 \\ \text { Suavidad } & 3103 & \\ \text { Trinidad } & 1{ }^{104} & \\ \text { Verdad } & 20105 & \end{array}$

90. 8,6,13 (Domine, adiutor meus et redemptor meus); 9,1,1 (Christe Iesu, adiutor meus et redemptor meus).

91. 1,$2 ; 2,2 ; 2,3 ; 2,5[2] ; 2,6 ; 2,12 ; 3,3$ (Mi redentor); 2,3 (Rey de Reyes, redentor del mundo); 2,7 (Mi criador y redentor); 3,8 (Redentor mío).

92. 1,9,14 (Auxilium et refugium meum); 3,3,5 (O tu praegrandis misericordia mea, deus meus, refugium meum a terribilibus nocentibus).

93. 1,15,24 (Tu domine, rex meus et deus meus); 1,19,30 (Rex noster); 11,19,25 (Regnator creaturae tuae).

94. Prol. (Rey y gloria mía); 1,1 (Rey celestial); 1,1; 2,5; 2,9 [2]; 3,1; 3,5 (Rey de gloria); 1,4; 1,7 (Rey mío); 1,6; 2,11; (O soberano rey); 1,8 (Clementísimo rey); 2,1 (Rey del cielo); 2,3 (Rey de reyes, redentor del mundo); 2,7 (Poderoso rey y rey de reyes); 2,11; 3,3 (Rey poderoso); 2,13; 3,2; 3,3; 3,8 (Rey celestial); 3,2 (Rey mío y Dios mío); 3,4; 3,7 (Rey del cielo); 3,9 (Rey y salvador mío).

95. 9,1,1 (Claritati meae, et divitiis meis et saluti meae).

96. 11,9,11 (Sapientia, sapientia); 11,11,13 (O sapientia Dei, lux mentium).

97. 3,1 (Sabiduría eterna); 3,5 (O sabiduría del eterno Padre)

98. 9,1,1 (Tibi, claritati meae, et divitiis meis, et saluti meae, domine deo meo); 9,4,12 (Deus salutis omnimodae); 10,23,33 (Deus, illuminatio mea, salus faciei meae, Deus meus); 10,35,56 (Deus salutis meae). Añadir 1,5,5 y 9,1,1 (Dic animae meae: salus tua ego sum).

99. 1,2 (Salud de nuestras almas); 1,5 (Salud de mi alma); 1,7 (Dulcísimo Jesús, salud del mundo); 2,7 (Señor y salud de mi alma); 2,11 (Salud nuestra y vida de todo lo que vive).

100. Prol. (Criador y salvador, Cristo Jesús); 1,6 (Mi salvador); 2,6; 2,10; 2,11; 3,1; 3,2 (Salvador mío); 2,9; 2,12; 3,3 (Salvador del mundo); 3,8 (Mi salvador Jesucristo); 3,9 (Rey y Salvador mío).

101. 4,3,5 (illius morbi tu sanator).

102. "Dans les Confessions, dominus, pris dans ce tissu serré d'emplois et de significations, revient aussi souvent et même plus souvent que deus. Son association à ce mot, domine deus, entre pour un quart dans les emplois de deus, ce qui rende manifeste le caractère révérentiel du terme" (S. Pôque, L'invocation, p. 928). Cf. nota 52.

103. 4,3,4 (Suavitas et origo iustitiae); 9,1,1 (Vera et summa suavitas); 10,17,26 (Vere bone, secura suavitas).

104. $12,7,7$ (Una trinitas et trina unitas)

105. $3,6,10$ (Veritas, veritas); 4,15,27 (Dulcis veritas); 4,16,31 (Domine Deus, veritas); 5,4,7 (Domine Deus veritatis); 7,10,16 (O aeterna veritas); 7,18,24 (Aeterna veritas); 8,10,24 (Deus verax); 10,26,37 (Veritas); 10,37,62 (Veritas); 10,40,65 (Veritas); 11,3,5 (Veritas); 
Vida

$\begin{array}{ll}11^{106} & 2^{107} \\ 5108 & 1^{109}\end{array}$

Virtud

5108

1109

El elenco nos dará pie para determinar diferencias de distinto calibre entre ambas obras. Una primera es perceptible a simple vista y se refiere a la mayor riqueza invocativa del Santo respecto del Beato. No se trata sólo del mayor número de títulos de uno respecto a otro ${ }^{110}$, sino incluso de la pluralidad de términos con que se expresa una misma realidad o aspectos de ella 111 .

Otros datos saltan a también a la vista. El primero, que, no obstante tener presente a la Trinidad a la hora de determinar componer su obra en tres libros, el Beato no la invoca como tal ni una sola vez. Agustín, en cambio, dos veces, una con el título mismo de Trinidad o la otra dirigiéndose nominalmente a las tres personas ${ }^{112}$. El segundo, que el Beato prescinde totalmente de los títulos que expresan las cualidades de Dios en sí mismo, presentes algunos de ellos en la obra agustiniana. El tercero es la preponderancia absoluta de los títulos "Dios" y "Señor" en uno y otro escrito. Son los títulos fundamentales que definen el ser del interlocutor (Dios) y su relación última con el hombre: él es el Señor ${ }^{113}$. Todos los demás pueden

11,23,30 (Lux, veritas); 12,10,10 (O veritas, lumen cordis mei); 12,25,35 (Iudex optime, deus, ipsa veritas); 12,30,41 (Deum nostrum, fontem veritatis); 13,24,36 (Lumen meum, veritas); $13,29,44$ (Tu verax et veritas). A añadir las veces en que dirigiéndose a Dios afirma: qui veritas es $(1,4,6 ; 3,6,10 ; 4,5,10 ; 5,3,5 ; 10,23,33 ; 13,25,38)$.

106. $1,4,4$ (Deus meus, vita mea, dulcedo mea sancta); $1,13,20$ (Deus, vita mea); $1,17,27$ (O vera vita, deus meus); 3,6,10 (Vita vitarum); 3,6,10 (Vita animae meae); 3,8,16 (Fons vitae); 7,1,2 (Vita vitae meae); 9,10,23 (Fontis vitae); 9,13,35 (Laus mea et vita mea, deus cordis mei); 12,25,34 (O vita pauperum, deus meus). A añadir 10,6,10 (Deus autem tuus etiam tibi vitae vita est); 12,11,13 (Et quae vita eius nisi tu?).

107. 2,11 (Salud nuestra y vida de todo lo que vive); 3.1 (vida de mi vida).

108. 1,13,23 (Virtus maritans mentem meam); 4,10,15 (Deus virtutum); 10,1,1 (virtus animae meae); 11,2,3 (Domine Deus meus, lux caecorum et virtus infirmorum statimque... virtus fortium). Cf. P. de LuIs, "Virtus animae meae" (Confessiones X,1,1), en Estudio Agustiniano 22 (1987) 77-132.

109. 1,3 (virtud y fortaleza).

110. 25 contra 49 en la presentación castellana, que ha unificado donde el latín diversificaba (rex et regnator; creator-conditor; lux-lumen, etc.). Pudiera parecer que el dato no es muy significativo en cuanto que se explicaría por la distinta extensión de una y otra obra. Pero la objección tendría pleno valor sólo si la estadística se refiriera al número de invocaciones y no a los títulos con que se hace la invocación.

111. Como ejemplo sirva la expresión por uno y otro la acción de Dios sobre el mundo. Mientras el Beato se limita al título de creador, Agustín recurre nada menos que a cinco (Artifex, Creator, Conditor, Moderator, Ordinator, Rector).

112. Cf. 13,12,13 (Pater, et Fili et Spiritu Sancte).

113. Cf. S. POQue, L'invocation, p. 928. 
ser entendidos como traducciones concretas, explicitaciones o especificaciones, de estos dos. Es normal, que aparezcan en uno y en otro autor como aposiciones de ellos. Pero junto a esta convergencia cuantitativa se da una divergencia muy significativa en cuanto que basta ella sólo para caracterizar diversamente a ambos escritos. Mientras en el agustiniano con uno y otro título se invoca casi siempre a Dios, sobreentendiéndose normalmente al $\mathrm{Pa}$ dre, en el de Fr. Alonso se invoca siempre a Jesucristo. El es el único interlocutor del Beato de principio a fin de su obra. A partir de estos datos, nada impide definir a la obra del Padre de la Iglesia como una obra teocéntrica, y a la del religioso castellano del siglo dieciséis como cristocéntrica. En efecto, es a él a quien invoca con los restantes títulos a que recurre. Todos ellos son cristológicos. El dato es obvio si pensamos en títulos que tradicionalmente son referidos exclusiva o casi exclusivamente a Cristo: Hijo, Defensor (1 Jn 2,1), Protector, Redentor, Salvador, Sabiduría (1 Cor 1,24), Salud (Jn 4,22), Vida (Jn 1,4; 11,25; 14,6), Virtud (1 Cor 1,24); es incluso normal en otros que, tras haber sido aplicados por la piedad anticotestamentaria a Dios, los cristianos prefirieron referirlos a Cristo: así Creador, Esperanza, Fortaleza, Gloria, Rey 114; pero es llamativo, si no el hecho, que no representa una novedad absoluta, sí la frecuencia y modalidades con que se dirige a Cristo con el título de Padre ${ }^{115}$.

Definimos a la obra agustiniana como teocéntrica, no obstante que Agustín se dirija también específicamente a Cristo en su invocación. Lo hace con los títulos siguientes: Cristo (Jesús), Médico, Redentor, Rey, Sabiduría. Pero salta a la vista que es una presencia más bien pobre en conjunto, sobre todo comparando términos con el Beato ${ }^{116}$. Detrás de todo ello está el hecho de que para Agustín, y particularmente en las Confesiones, Cristo es ante todo el Mediador $(7,18,24 ; 10,42,67-43,69)$. Es, sin duda, también la Verdad y la Vida, mas él prefiere acentuar su función de camino para llegar a ellas $(7,21,27)$.

114. Sorprende el amplio recurso del Beato a este título, al que sólo superan en frecuencia los títulos fundamentales de Dios y Señor y éste último por muy poco (29 presencias contra 27). A lo que hay que añadir las tres veces que utiliza el título de Majestad y el de Clemencia, Fortaleza, Poder soberano. Cabe pensar que el apogeo del rey Felipe y del imperio español haya estimulado el uso del mismo.

115. Padre de la(s) misericordia(s) $(1,1 ; 1,3 ; 1,6 ; 2,4 ; 2,11)$, padre piadosísimo $(1,5 ; 1,9)$; Padre mío y Criador (1,5); padre de piedad $(2,12)$; misericordioso Padre $(2,13)$. El título de "Padre" no es ninguna novedad del Beato. Aparece ya en la antigüedad, por e., en MELITON DE SARDES, Homilía sobre la Pascua, 9. Cf. G. RACE, A propos du Christ-Père dans l'Homélie Pascale de Méliton de Sardes, en Recherches de Science Religieuse 50 (1962) 400-408.

116. Los dos ejemplos más significativos los tenemos en Rey (27 presencias en el Beato, 2 en el Santo) y en Redentor (12 contra 2 respectivamente). Añádase que mientras el Beato le invoca 12 veces con el título de Salvador, el Santo no lo hace ninguna, aunque aquí pudieran entrar consideraciones de tipo linguístico (cf. C. MOHRMANN, Considerazioni, 310). 
Tanto el Beato como el Santo participan de la fe en la doble naturaleza, humano y divina, de la única persona divina de Cristo. A nivel de oración dicha fe implica dos formas de considerar y de acercarse a Cristo, que al Santo le gusta exponer. Ésta es una de sus fórmulas: "Presentemos nuestras preces a tan gran intercesor: El otorga juntamente con el Padre lo que pidió al Padre, puesto que es mediador y creador; mediador para pedir, creador para conceder" 117. En fórmula más breve, también suya: "Con nosotros pide y con el Padre concede" 118. Dos modos, pues, de acercarse a Cristo, que no se excluyen. Agustín ha elegido preferentemente el primero, Fr. Alonso exclusivamente el segundo. Dos razones, estrechamente relacionadas entre sí, se pueden dar de dichas preferencias. La primera lleva el sello personal, la segunda el eclesial.

La distinta historia religiosa personal de cada uno conduce ya de por sí a una opción con preferencia a la otra. Desde la lectura de los libros neoplatónicos, Agustín tuvo muy clara la distinción entre la patria, que supieron mostrarle, y el camino para llegar a ella, que no le ofrecieron ellos, y sí San Pablo. Desde esa experiencia Cristo fue para él ante todo el mediador que le facilitó el acceso a Dios (Padre). La dificultad de encontrar a Dios y la experiencia del extravío originaron que en su oración mirase a Cristo sobre todo en esa función mediadora para alcanzar la meta que buscaba 119 . Fr. Alonso, en cambio, que vivió siempre en la seguridad de la verdad, tenía menos experiencia de la necesidad de mediación. Por eso, a la hora de integrar a Jesús en su oración, le mira ante todo en su realidad divina, y le dirige a él directamente su oración.

Pero dicho esto, no está dicho todo, pues no hemos de presentar como peculiaridad del Beato lo que en ningún modo lo fue. La experiencia vivida por él no fue exclusiva suya, sino compartida con la sociedad cristiana de su tiempo. Por eso, el mencionado cristocentrismo lo comparte también con la espiritualidad de su época 120.

Otro punto, una nueva diferencia, resalta de la comparación de los títulos utilizados por uno y otro autor, en cierta conexión con lo anterior. Mientras en el Beato apenas encontramos a Dios (Cristo) como Verdad, es éste quizá el aspecto más resaltado por el Santo. Basta con fijarse en la frecuencia con que recurre a los dos títulos principales que recogen esa idea: Luz (16

117. Sermón $223 \mathrm{~F}$ (=Wilmart 6),3.

118. Sermón 105,1. Cf. también 175,$3 ; 217,1 ; 245,4$.

119. Por otra parte, ha sido siempre el lenguaje de la oración litúrgica, dirigida al Padre por mediación de Jesucristo.

120. Respecto al renacimiento espiritual español, escribe M. Andrés, "todos están de acuerdo en llamarlo cristocentrista" (La teología española en el s. XVI. Madrid 1977, p. 152). 
presencias), Verdad (20) ${ }^{121}$, ninguno de los cuales aparece en la obra orozquiana. Para explicarlo, de nuevo hemos de pensar en la experiencia personal de ambos autores. Por una parte, Agustín, como filósofo, se ocupó permanentemente del problema de la relación de la mente humana con la verdad. La solución que ofrece se fundamenta en la participación por ella en la luz y verdad divinas. En su relación con Dios no olvida esta faceta de su pensamiento. Por otra parte, no se puede olvidar el hecho de que Agustín vivió la experiencia, ampliamente narrada en las Confesiones, del error maniqueo, metafísico y religioso a la vez, y que al hablar de su conversión la describe como la percepción de una luz de seguridad $(8,12,30)$, contrapuesta, sin duda, a la otra luz, categoría fundamental en el sistema gnóstico. Ni se ha de olvidar tampoco que su actividad pastoral estaba marcada al momento de escribir la obra por la polémica contra el mismo error. Nada extraño que, tanto desde la referencia personal, como desde la referencia a aquellos a quienes servía como pastor, sintiese la necesidad de dirigirse a Dios que ilumina, ya para salir del error, ya para evitar caer en él. Por su parte, el Beato, como la sociedad cristiana española de la época, no experimentó a nivel intelectual los problemas que acuciaron a Agustín; como indicamos, vivió siempre seguro de la verdad. La misma reforma protestante que podía haber orientado los espíritus en una dirección de búsqueda, lo que hizo fue cerrarlos en las posiciones adquiridas. La teología, más que de búsqueda, fue sobre todo de apologética y de confirmación del depósito adquirido. En la España católica, en general, nunca cupo la menor duda de la posesión de la verdad en pleno. Nada extraño tampoco, pues, que el Beato no invoque a Dios (Cristo) con títulos que le relacionen con la verdad.

Para entrar de alguna manera en la experiencia religiosa de cada uno de nuestros autores, quizá no haya otro camino más adecuado que dejar de lado los títulos ya clásicos en teología como los de Dios, Amor, Padre, Señor, Sabiduría, Salvador, Redentor, Creador, Rey y detenernos en los demás cuyo uso hay que atribuir más a la propia vivencia que a la "escuela".

La imagen espiritual que el Obispo de Hipona nos deja de sí es la de un hombre que lucha por vivir en la verdad, por alcanzar la verdadera vida, por hacerse perdonar su pecado, por alcanzar todo lo que apetece, aunque en Dios, y ser feliz. Comienza mirando a sí mismo y desde su situación personal busca los títulos de Dios que más eficaces pueden resultarle y con ellos le invoca. Nadie se sentirá sorprendido si afirmamos que Agustín se reconoce ante todo como un enfermo, pero no deshauciado ni tampoco desesperado. Más exactamente diríamos que como un convaleciente. En este contexto se

121. A los que hay que añadir otros como Iluminación, Iluminador. 
comprenden las invocaciones con los títulos de Médico, Sanador, Salud, y sobre todo, Vida. Por otra parte, él es sabedor de sus miserias, por lo que invoca a Dios como corazón que se apiada ${ }^{122}$, como Misericordia, nada menos que nueve veces.

Pero Dios, para Agustín, no es sólo alguien, el único, que puede liberarle del peso de su pasado, razón del uso de los títulos que acabamos de mencionar; también piensa en él como el único capaz de saciar todas las apetencias humanas, es decir, placer, bienes y gloria, que en su versión pecaminosa están representados en las tres concupiscencias de $1 \mathrm{Jn}$ 2,16, la de la carne, la de los ojos y la de ambición del mundo. Agustín sabe que Dios es todo eso que anhela y le invoca desde ese saber. El placer, que el hombre carnal pone en los sentidos, Agustín lo ubica en Dios: de aquí títulos como Luz, Dulzura, Suavidad, Pan, Descanso, que pertenecen al lenguaje de los sentidos, de los que se sirve la concupiscencia de la carne ${ }^{123}$. La belleza y riqueza que aquél encuentra en los bienes pasajeros, Agustín las coloca en Dios, a quien se dirige con los títulos de Hermosura y Riquezas. Lo que el hombre busca en sus relaciones con sus congéneres, lo es Dios, al que invoca con los títulos de Excelsitud, Honor, Decoro, Brillo, Alabanza ${ }^{124}$.

Muy distinto a éste, y menos rico, es el retrato que sacamos del Beato Orozco. El se siente ante todo como "vasallo" ante el Señor Poderoso, ante el Rey ${ }^{125}$. A él reverencia, de donde la invocación con el título de Majestad. Reconoce su poder, convirtiéndolo en título con el que lo invoca, aunque una única vez, junto con el de Aguila poderosa. Ante él no está exento de algún temor, lo que justifica el título de Clemencia. De él espera protección, defensa y, ante todo, honores, lo que explica las diez veces que le invoca con el título de Gloria ${ }^{126}$. Sin duda aquí sale a relucir la España caballeresca. En el fondo se trasluce el espíritu de la época de El Quijote 127.

122. La misericordia consiste en com-padecer libremente la miseria de otro (Conf. 3,3,3: "Cum ipse patitur miseria, cum aliis compatitur, misericordia dici solet"). Es el miserum cor, el corazón que comparte por amor la miseria ajena.

123. Cf. $4,7,12 ; 10,6,8 ; 10,27,38$.

124. Cf. $2,5,10$.

125. Recordamos lo dicho en nota 114 sobre la frecuencia de este título.

126. Sólo una vez se dirige a él como "Gloria de los ángeles"; en todas las demás ocasiones como "Gloria mía". Nótese que por el título de rey adquiere la forma de "rey de gloria" (no "rey de la gloria") 6 veces.

127. En el conjunto, apenas cabe atribuir significado a los otros tres títulos que no hemos tomado en consideración : Dulcedumbre, que puede ser un eco de la "dulzura" agustiniana; a Piélago de amor, y a Mar. 


\section{CONCLUSION}

La comparación entre las dos obras se podía extender a más campos. Pero los puntos sobre los que la hemos establecido son suficientes para hacer un balance general.

La primera constatación es que, no obstante que se notan dependencias textuales, ambas obras se encuentran muy distantes entre sí. Tienen, es obvio, puntos comunes, además del título. Ante todo, la forma de plegaria y el lenguaje de la invocación. En una y otra obra nos encontramos con una piedad sincera y profunda. Ambos hablan desde el corazón, expresando sus vivencias íntimas. Coinciden en el tono general de alabanza y gratitud por los dones recibidos de Dios. También en la actitud subjetiva interior, sincera y compungida, de quien se sabe pecador. Pero aunque no hay mayor diferencia en la mencionada actitud de uno y otro "confesor", sí la hay en la "materia" de una y otra "confesión". Lo cierto es que Agustín ha logrado mejor que el Beato convencer a sus lectores de que fue un gran pecador, aunque la realidad no sea enteramente tal. En definitiva, coinciden en ciertos aspectos subjetivos, justamente porque el Beato intentó imitar al Santo.

Pero la voluntad de imitar no produce sin más el éxito en la imitación. La obra creadora requiere algo más que voluntad. Detrás de ella está siempre la índole peculiar de cada autor, acompañada por sus circunstancias de lugar y tiempo, que dan razón de las divergencias entre las dos obras homónimas.

La historia espiritual de Fr. Alonso fue fundamentalmente rectilínea, mientras en la de Agustín prevaleció la línea quebrada. La primera deja poco espacio para la sorpresa, que es la gran baza de la segunda, al menos a nivel narrativo. Una vez que se han leído unos capítulos de la obra del Beato, ya se intuye lo que van a ser los siguientes, cosa que no acontece en las Confesiones agustinianas donde el suspense está casi siempre servido. $\mathrm{Su}$ propia vida personal ofrecía a Agustín material más rico y variado.

Pero no es todo. A esa mayor riqueza y variedad hay que añadir la diversa capacidad para analizarla y contarla. Es evidente que el Beato no maneja los recursos de la retórica como Agustín, que había hecho de ella su profesión, ejercida durante varios años. En su haber hay que poner sin duda una buena parte de la fascinación que ejerce sobre el lector. No se puede olvidar que la retórica antigua no se reducía a la simple estética de la palabra. Siendo lugar de confluencia de los demás saberes, los ponía todos al servicio del arte de la comunicación. Y el Obispo de Hipona supo hacerlo con maestría. 
Por otra parte, a nivel teológico-religioso, a Agustín se le puede considerar como un autodidacta, mientras que Fr. Alonso es hijo de la "Escuela", con lo que ello implica. El autodidacta refleja lo que ha aprendido en sí mismo y por sí mismo, el "escolástico" la experiencia común. Por eso el primero suele sorprender más, mientras que el segundo puede ser más metódico, pero también más ordinario. Es lo que sentimos al leer una y otra obra.

Pero no hay autodidacta absoluto. En última instancia todo el que aprende lo hace en alguna "escuela". Aunque no vaya al colegio, el niño halla su escuela particular en su casa, en la calle donde juega. Más allá de la institución, todo se convierte en escuela, todo nos enseña, de todo aprendemos. La escuela en que nuestros autores se educaron como cristianos fue la Iglesia de que formaron parte. Ahora bien, aun siendo la misma Iglesia de Cristo, no se presenta igual en el final del siglo cuarto en Africa que en el siglo dieciséis en España. Dígase lo mismo de Dios: aún siendo el mismo, no lo veían igual los hombres de un siglo que los del otro, porque el hombre es también historia. Nos resultó claro de la comparación entre los títulos de advocación a que recurren uno y otro autor.

Pío de LUIS 